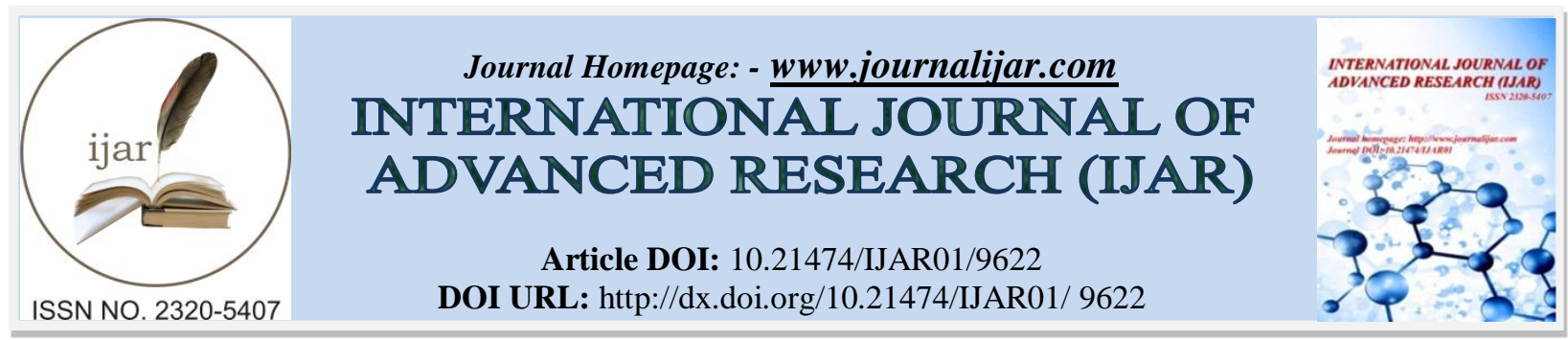

RESEARCH ARTICLE

\title{
IMPORTANCE OF AMMONIUM MOLYBDATE TEST IN ALUMINIUM PHOSPHIDE POISONING: A CASE STUDY.
}

Pooja S. K. Rai ${ }^{1}$, Kanchan Sonone ${ }^{2}$ and Pramod W. Ingale ${ }^{3}$.

1. Associate Professor, Department of Biochemistry, LTM Medical College, Sion, Mumbai, Maharashtra, India.

2. Assistant Professor, Department of Biochemistry, LTM Medical College, Sion, Mumbai, Maharashtra, India.

3. Professor \& Head, Department of Biochemistry, LTM Medical College, Sion, Mumbai, Maharashtra, India.

\section{Manuscript Info}

Manuscript History

Received: 02 July 2019

Final Accepted: 04 August 2019

Published: September 2019

Key words:-

Aluminum phosphide, Phosphine, Poisoning, Suicide.

\section{Abstract}

Suicidal tendencies are one of the major social problems worldwide. It is equally seen in Indian population. Aluminum phosphide (AIP) is highly toxic pesticide which is commonly used for grain preservation. Poisoning with AlP has usually occurred in attempts to suicide. It is a more common case in adults rather than teenagers. In some eastern countries it is a very common agent with rapid action for suicide. Up to date, there is no effective antidote or treatment for its intoxication. Silver nitrate filter paper test is a simple test for early diagnosis of Aluminum phosphide poisoning. But for confirmation Ammonium Molybdate is confirmatory test.

Copy Right, IJAR, 2019,. All rights reserved.

\section{Introduction:-}

Aluminum phosphide (AIP) is a solid fumigant which has been extensively used since the 1940s. AlP is a solid pesticide that rapidly became one of the most commonly used grain fumigants because of its properties which are considered to be near ideal; it is toxic to all stages of insects, highly potent, does not affect seed viability, is free from toxic residues and leaves little residue on food grains ${ }^{[1]}$. It is easily available and is purchased in some countries such as India under trade names e.g. Celphos, Quickphos, Synfume and Phosfume ${ }^{[2]}$.

\section{Clinical manifestations:}

1. 17 years old male patient came with altered sensorium and difficulty in breathing. Accompanying relatives gave history of consumption of unknown poison 3-5 hours before these episodes.

2. On Examination : Patient was comatose, pupils were fully dilated, Doll's eye positive, corneal reflex present with Persistent Bradycardia (42-62/min).

3. Symptomatic treatment was initiated. Silver nitrate test on Gastric lavage sample was positive. Then standard treatment for Organo-phosphorus poisoning was done but there was no improvement in the patient.

4. Then Lead acetate test was done to rule out sulphur compounds such as Hydrogen Sulphide .

5. Ammonium Molybdate test was performed to confirm the Aluminium Phosphide poisoning. As Aluminum phosphide causes multiorgan Failure so patient died.

Corresponding Author:-Pooja S. K. Rai.

Address:-Associate Professor, Department of Biochemistry, LTM Medical College, Sion, Mumbai, Maharashtra, India. 


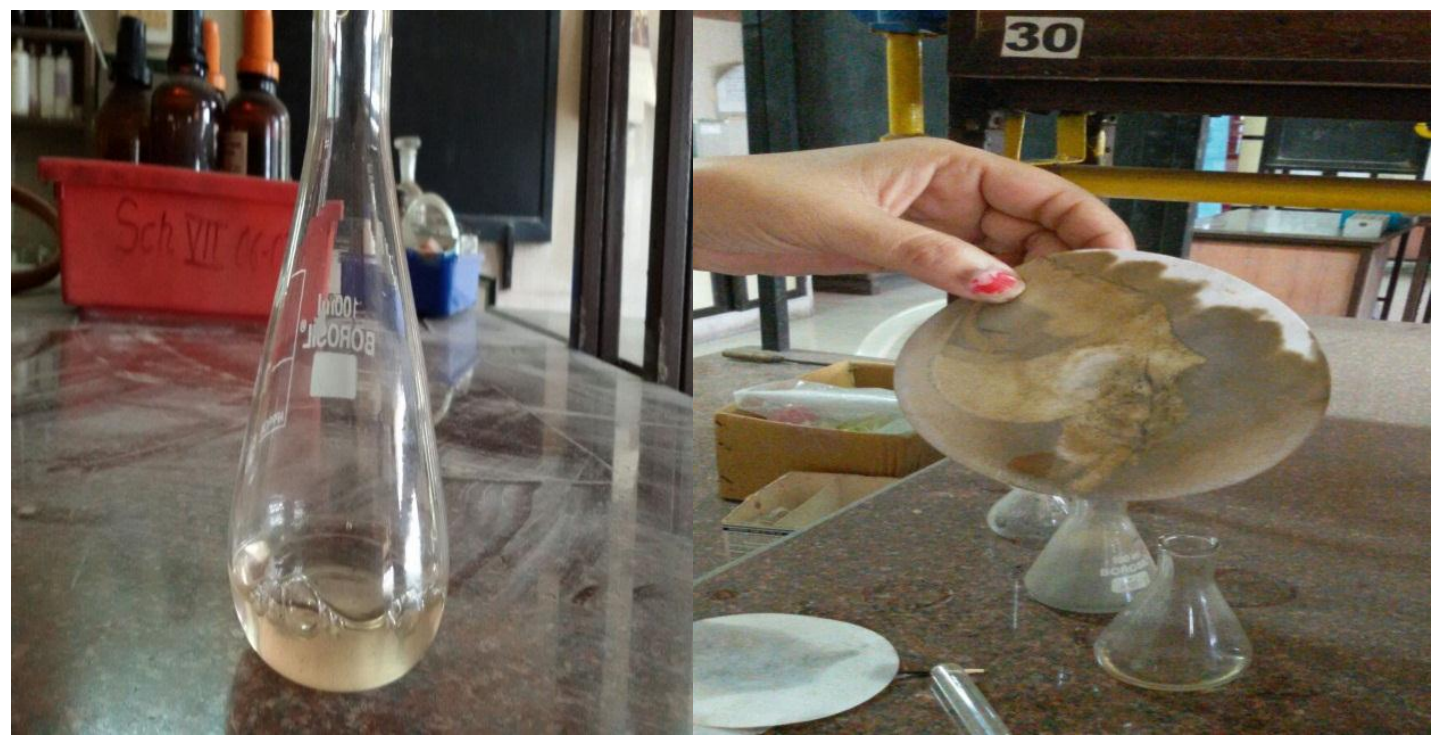

Gastric Aspirate

Silver Nitrate Filter Paper test

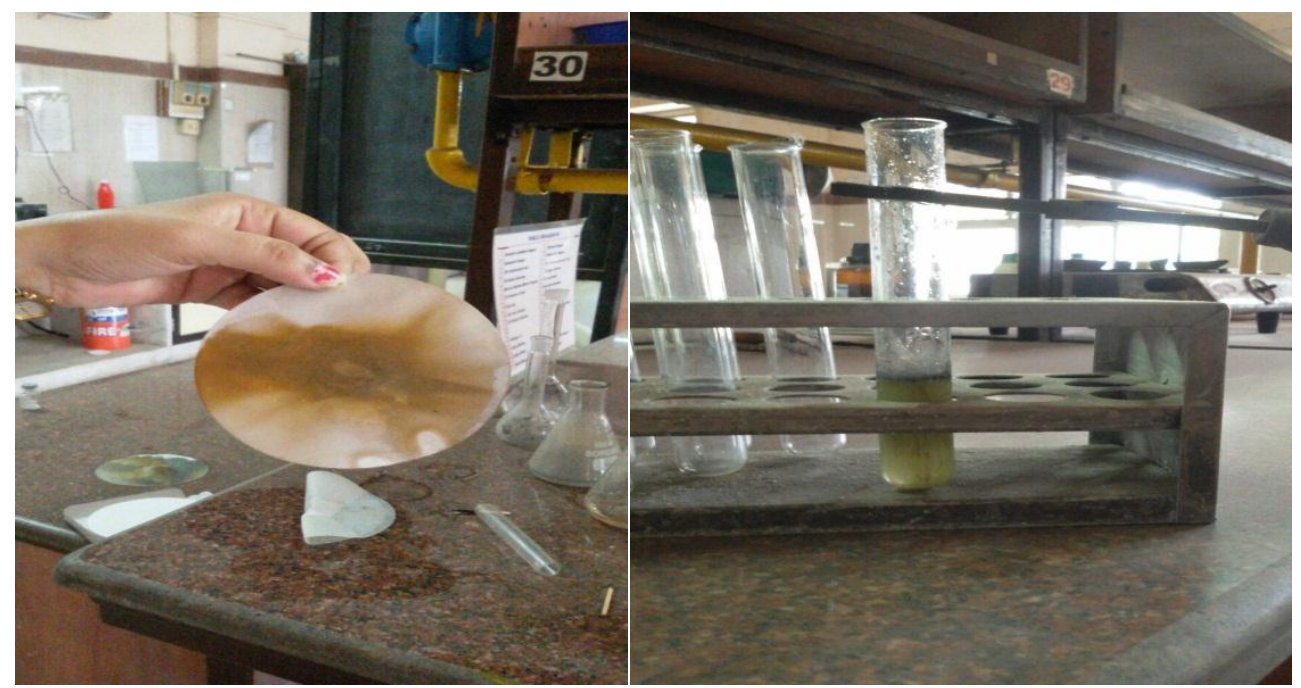

Silver nitrate + Lead acetate Test

Ammonium Molybdate Test

\section{Silver Nitrate Filter Paper test}

1. Principle: Phosphene gas reduces $\mathrm{AgNO}_{3}$ to metallic Silver ( $\mathrm{Ag}$ ) which gives black colour.

2. Procedure: Take $5 \mathrm{ml}$ of gastric aspirate with $15 \mathrm{ml}$ of water in flask and cover its mouth with a filter paper impregnated with silver nitrate $(0.1 \mathrm{~N})$. On heating this at $50^{\circ \mathrm{c}}$ for $15-20$ minutes, blackening of filter paper develops which is indicative of presence of phosphene ${ }^{[3-5]}$.

3. Result: Black colour due to formation of Metallic Silver.

4. Inference: Phosphene gas / Hydrogen sulphide present.

\section{Problems with silver nitrate test :}

As such silver nitrate test is a $100 \%$ sensitive test for detection of aluminium phosphide. But it also gives positive reaction with sulphur compounds. It is invariably seen that visceras sent for chemical examination, due to delay in transportation and examination and improper preservation, get decomposed. Hydrogen sulphide is one of the gases that are liberated during decomposition. This hydrogen sulphide can react with silver nitrate giving a false positive reaction for aluminium phosphide. 


\section{How to avoid false positive reaction?}

Normally filter paper impregnated with silver nitrate solution is used. But to exclude presence of sulphides filter paper impregnated with silver nitrate and lead acetate solution should also be used. If only the silver nitrate paper is blackened then phosphorus or phosphides may be present. If both papers are blackened then sulphides may be present and the result is inconclusive. In that situation the confirmatory ammonium molybdate test should be carried out ${ }^{[6-7]}$.

\section{Ammonium molybdate test :}

1. Principle: Upon warming with ammonium molybdate in presence of nitric acid, inorganic phosphates are precipitated as canary yellow ammonium phosphomolybdate.

2. Procedure: $3 \mathrm{ml}$ of gastric sample + few drops of conc. $\mathrm{HNO}_{3}+\mathrm{Pinch}$ of ammonium molybdate $\rightarrow$ canary yellow colour. ${ }^{[3]}$

3. Result: Canary yellow colour due to formation of Ammonium Phosphomolybdate.

4. Inference: Phosphene gas is present.

\section{Discussion:-}

Diagnosis is made by laboratory and clinical tests. The factors of positive history of ingestion, symptoms compatible with AIP ingestion and chemical test for phosphine positive in gastric aspirate and breath alone or in combination would help the diagnosis. The breath of AlP intoxicated patients has a garlic-like odour. The plan of diagnosis is based on the patient's history and a positive result (blackening) on tests of the patient's breath with paper moistened with fresh silver nitrate solution due to exhalation of $\mathrm{PH}_{3}$ or by biochemical analysis of blood or gastric aspirate for phosphine ${ }^{[8-10]}$.

Using filters impregnated with silver nitrate ${ }^{[11]}$ and ion chromatographic methods ${ }^{[12]}$ were recruited to determine phosphine in the bio-samples. Gas chromatographic procedure in survivors ${ }^{[13-15]}$ and post-mortem specimens ${ }^{[16]}$ has been developed for the measurement of phosphine levels.

Gas chromatographic technique using a nitrogen phosphorus detector has been introduced for phosphine measurement in post mortem stomach contents, blood, and liver specimens ${ }^{[17]}$.

Laboratory assessment is mainly done to obtain the prognosis. Leucopenia indicates severe AlP toxicity. Increased serum glutamic oxaloacetic transaminase (SGOT) or serum glutamic pyruvic transaminase (SGPT) and induced metabolic acidosis indicate moderate to severe AlP overdose. Decreased plasma magnesium level has been reported while potassium might have been increased or decreased ${ }^{[18]}$. Plasma raised level of renin is significant as its level has a direct relationship with mortality and proportion to the dose of AIP. The serum level of cortisol is usually decreased in severe AlP poisoning ${ }^{[19]}$.

It has been demonstrated that AlP can induce hepatotoxicity. The main findings were sinusoid congestion, fatty liver changes, central vein congestion, destruction of nucleus of hepatocytes and centrilubolar necrosis. Manifestations of hepatotoxicity usually develop 72 hours after AlP intoxication. Death due to acute hepatocellular toxicity and fulminant hepatic failure has also been reported in acute intoxication.

Cardiovascular and respiratory system changes can also lead to death ${ }^{[20]}$. Patients may demonstrate hyperglycemia and metheomoglubinemia ${ }^{[21]}$. Development of refractory shock, ARDS, aspiration pneumonitis, anaemia, metabolic acidosis, electrolyte imbalance, coma, severe hypoxia, gastrointestinal bleeding, and pericarditis may be observed following acute AlP poisoning but these manifestations are associated with poor prognosis.

\section{Conclusion:-}

1. Gastric $\mathrm{AgNO}_{3}$ filter paper test is a simple test, which is used for detection of Aluminium Phosphide and hydrogen sulfide in Gastric sample.

2. As Aluminium Phosphide poisoning has very high mortality rate and is often confused with organo-phosphorus and other sulfide poisoning, so in addition to silver nitrate, lead acetate solution should also be used for sulfides.

3. Ammonium Molybdate test ${ }^{[6-7]}$ on gastric sample can confirm Aluminium Phosphide poisoning and save a precious life. It is suggested to carry out this test in all suspected cases. 


\section{References:-}

1. Wahab A, Rabbani MU, Wahab S, Khan RA. Spontaneous self-ignition in a case of acute aluminium phosphide poisoning. Am J Emerg Med. 2009; 27:752-756.

2. Chopra JS, Kalra OP, Malik VS, Sharma R, Chandna A. Aluminium phosphide poisoning: a prospective study of 16 cases in one year. Postgrad Med J. 1986; 62:1113-1115.

3. Krishan Vij. Textbook of forensic medicine and toxicology, principles and practice.2nded. New Delhi. B. I. Churchill Livingstone Pvt. Ltd. Section II chapter 14.

4. Dr. K.S. Narayan Reddy. The essentials of forensic medicine and toxicology. 22nded. Hyderabad. K Suguna Devi. Chapter 25.

5. V.V. Pillay. Handbook of forensic medicine and toxicology. 13thed. Hyderabad. Paras Publisher. pp 342.

6. Basic analytical toxicology, international programme on chemical safety. World HealthOrganization, Geneva. 1995. pp 206.

7. Prof. T.D.Dogra, Lt. Col. Abhijit rudra editors. Lyon's medical jurisprudence and toxicology. 11thed. New Delhi. Delhi law house. pp 1308.

8. Khosla SN, Nand N, Khosla P. Aluminium phosphide poisoning. J Trop Med Hyg. 1988; 91:196-198.

9. Mital HS, Mehrotra TN, Dwivedi KK, Gera M. A study of aluminium phosphide poisoning with special reference to its spot diagnosis by silver nitrate test. J Assoc Physicians India. 1992; 40:473-474.

10. Demange M, Elcabache JM, Grzebyk M. et al. Phosphine sampling and analysis using silver nitrate impregnated filters. J Environ Monit. 2000; 2:476-482. doi: 10.1039/b001990i.

11. Carlson M, Thompson RD. Determination of phosphine residues in whole grains and soybeans by ion chromatography via conversion to phosphate. J AOAC Int. 1998; 81:1190-1201.

12. Gras R, Luong J, Hawryluk M, Monagle M. Analysis of part-per-billion level of arsine and phosphine in light hydrocarbons by capillary flow technology and dielectric barrier discharge detector. J Chromatogr A. 2009; 1217:348-352.

13. Norman KN, Leonard K. Gas chromatography-mass spectrometry determination of phosphine residues in stored products and processed foods. J Agric Food Chem. 2000; 48:4066-4070.

14. Roels J, Van Langenhove H, Verstraete W. Determination of phosphine in biogas and sludge at ppt-levels with gas chromatography-thermionic specific detection. J Chromatogr A. 2002; 952:229-237.

15. Musshoff F, Preuss J, Lignitz E, Madea B. A gas chromatographic analysis of phosphine in biological material in a case of suicide. Forensic Sci Int. 2008; 177:e35-38.

16. Chan LT, Crowley RJ, Delliou D, Geyer R. Phosphine analysis in post mortem specimens following ingestion of aluminium phosphide. J Anal Toxicol. 1983; 7:165-167.

17. Chugh SN, Juggal KL, Sharma A, Arora B, Malhotra KC. Magnesium levels in aluminium phosphide poisoning [Abstract] J Assoc Physicians India. 1990; 38:32.

18. Chugh SN, Ram S, Sharma A, Arora BB, Saini AS, Malhotra KC. Adrenocortical involvement in aluminium phosphide poisoning. Indian J Med Res. 1989; 90:289-294.

19. Gupta MS, Malik A, Sharma VK. Cardiovascular manifestations in aluminium phosphide poisoning with special reference to echocardiographic changes. J Assoc Physicians India. 1995; 43(773-774):779-780.

20. Jain SM, Bharani A, Sepaha GC, Sanghvi VC, Raman PG. Electrocardiographic changes in aluminium phosphide (ALP) poisoning. J Assoc Physicians India. 1985; 33:406-409.

21. Shadnia S, Mehrpour O, Soltaninejad K. A simplified acute physiology score in the prediction of acute aluminum phosphide poisoning outcome. Indian J Med Sci. 2011; 64:532-539. 